\title{
Direction for Artificial Intelligence to Achieve Sapiency Inspired by Homo Sapiens
}

\author{
Mahmud Arif Pavel \\ Dept. of Biological Sciences \\ St. John's University \\ NY, USA
}

\begin{abstract}
Artificial intelligence technology has developed significantly in the past decades. Although many computational programs are able to approximate many cognitive abilities of Homo sapiens, the intelligence and sapience level of these programs are not even close to Homo sapiens. Rather than developing a computational system with the intelligent or sapient attribute, I propose to develop a system capable of performing functions that could deem as intelligent or sapient by Homo sapiens or others. I advocate converting current computational systems to educable systems that have built-in capabilities to learn and be taught with a universal programming language. The idea is that this attempt would help to attain computational actions in artificial means, which could be viewed as similar to human intelligent and sapient acts. Although this paper is seemingly speculative, some feasible elements are proposed to advance the field of Artificial Intelligence.
\end{abstract}

Keywords-artificial sapience; sapient agent; artificial intelligence; bio-inspired AI

\section{INTRODUCTION}

Homo sapiens ('wise man' in Latin, coined by Carl Linnaeus in 1758) is unique and foremost among the rest of the creatures because of the breadth of Homo Sapiens' wisdom [1], [2]. Wisdom or sapience is the ability to reflect the act of using knowledge and experience [3], [4]. Beside a philosophical explanation of wisdom [2], [5], [6], a formal academic concept of computational or artificial sapience (wisdom) has been developed considering the aspect of the learning, adaptation, and judgment capabilities [4], [7], [8]. However, in this paper, I will define a sapient system simply as a computational entity that can generate functions or actions that are deemed smart and wise by Homo sapiens or others. Many believe that the peak of Artificial Intelligence (AI) will be achieved when AI can learn and perform every intelligence or sapience based act of Homo Sapiens (HS) - though winning this achievement seems very distant [9], [10].

Hitherto, most AI researchers place substantial effort to attain the automation of jobs that humans can perform [11]. However, the current paradigm of AI research is shifting to the development of AI that can be teachable or trainable to perform work as similar to what humans learn to perform [11][13]. Indeed, when AI is trained, it could display exceptional ability such as generating a sensible explanation of image regions in natural language statements [14]. Therefore, it is fair to assume that building a simple educable AI is the critical step to achieve HS level intelligence [8], [11]. Yet the development of such simple AI is expected to be difficult and take many years of study and investigation. For simplicity, to describe an AI agent that can be taught and trained, henceforth I will name it as Artificial Sapiens (AS) as the ultimate goal of this agent is to become Homo sapiens.

One of the approaches to achieve AS is to mimic how HS thinks and works [10]. HS provides the necessary hints on how to advance the current AI to AS level [7], [15]. Artificial neural networks and behavior dependent robots, personal digital assistants are few examples of AI inspired by HS [16]. However, the functionalities of these examples are only slightly equivalent to HS. To propose a step towards the development of an AS, I have taken the inspiration from the early development of HS. HS learns and develops from its childhood to adulthood [17], [18]. Implementing the very fundamental methodology of the HS learning process is now a well-suggested strategy to achieve an educable AI i.e. the Artificial Sapiens [11], [12]. Though achieving AS will be very difficult, here I will describe a plan to bring this endeavor one step forward.

I first examined the attempt to obtain an AS by mimicking HS child learning capabilities. I then proposed to transform the current non-intellectual electronic device such as a desktop computer, laptop, mobile phone or other to an Artificial Sapiens - by simply giving their operating systems (OS) and applications with a learning capability.

To get an idea how to change an OS to AS, I compared the human system to software and hardware of the computer. I presented an alternative approach to the comparison rather than customarily comparing computer system to human brain system [19]. To generate a teachable and trainable OS, I proposed to make the subprograms (applications) of the OS programmable with a universal programming or teachable language by its ordinary users. Inspired from how a child learns from 'Do' or 'Do not do' statements and develops wisdom (sapience) [18], my idea is when applications are programmed to modify its own output through interactions with its users, it could display a level of intelligence or sapience. I presented a few examples of intelligent or sapient acts that could be achieved by programmable or teachable applications within non-intellectual operating systems. Certainly, I do not pretend to have expertise on this matter but here I offered some observations from the biological perspective that could have some potential to achieve HS level AS. 


\section{A CHILD COMPUTER}

Before achieving an adult level sapient system, making a computer/AI system that simulates a child is one of the core goals of AI researcher [10], [13]. Although something like the child computer is overly optimistic, this is a necessary step to generate a HS level AS since HS continuously learns to be a sapience from its childhood to adulthood [11], [12]. HS has the knowledge, learning and skill acquisition ability - the mechanism is present at the very birth[18], [20]. HS has the ability to be taught by others or by own self through observation, imitation, assimilation and experimentation. HS employs existing knowledge and skills, and burgeons with more knowledge and skills [6], [8]. A childlike computer should have the above ability to learn like HS and to grow to a higher maturity level. Considering that the child-brain can be programmed, the current approach is to make a device or a robot that mimics a child or parts of a child's ability [21]. However, there is still no such HS level child computer or close to it. It seems too difficult to create. In this paper, I propose to convert existing computational devices (e.g. laptop or mobile) to a child-like system. At the beginning of a child's learning stage, an adult HS mostly teaches a child what to do or what not to do [17], [18], [20]. Similarly, current devices could have functions that can be done or cannot be done based on its users' instructions. In other words, these devices could learn what to do or what not to do from its users. These teachable devices, then, can grow as they continuously learn and evolve to show a level of intelligence or sapience. Thus, these devices can also be attributed as Artificial Sapiens. In the next sections, I will elaborate more about how to obtain a teachable device based on the comparison between a human and a computer.

\section{NEW PARAdigm OF COMPARISON BETWEEN COMPUTER AND HOMO SAPIENS}

There are many AI systems that are inspired by biology [15], [16]. Observation of real life could provide valuable insights on the plausible design of Artificial Sapiens systems. Real life comparison of AI is often limited to the comparison of the computer with the brain of HS [19]. The focal point of comparison between HS and Computer/AI is that the computer inputs, stores, processes, and outputs information somewhat similar to an HS brain. A few basic differences between HS and computer information processing include central versus distributed control, sequential versus parallel input, exclusive versus overlaid output, and low versus high self-processing [19]. The current comparison between HS and computer/AI is less focused on how to achieve better human intelligent or sapient activity. Therefore, here I revisit the original comparison by drawing further inspiration from real HS systems. I explored an alternative comparison by trying to resemble the whole HS system with a computer system.

\begin{tabular}{|c|c|c|}
\hline $\begin{array}{c}\text { Computer } \\
\text { Devices }\end{array}$ & $\begin{array}{c}\text { External } \\
\text { Input }\end{array}$ & $\begin{array}{c}\text { Internal } \\
\text { Output }\end{array}$ \\
\hline Webcam & Light & Electrical signals \\
\hline Microphone & Sound & Electrical signals \\
\hline
\end{tabular}

\begin{tabular}{|c|c|c|}
\hline $\begin{array}{c}\text { Computer } \\
\text { Devices }\end{array}$ & $\begin{array}{c}\text { Internal } \\
\text { Input }\end{array}$ & $\begin{array}{c}\text { Internal } \\
\text { Output }\end{array}$ \\
\hline Processor & $\begin{array}{c}\text { Electrical } \\
\text { signals }\end{array}$ & $\begin{array}{c}\text { Process } \\
\text { instructions that } \\
\text { drive a computer }\end{array}$ \\
\hline Hard Disk & $\begin{array}{c}\text { Electrical } \\
\text { signals }\end{array}$ & Store information \\
\hline
\end{tabular}

\begin{tabular}{|c|c|c|}
\hline $\begin{array}{c}\text { Computer } \\
\text { Devices }\end{array}$ & Internal Input & $\begin{array}{c}\text { External } \\
\text { Output }\end{array}$ \\
\hline Monitor & $\begin{array}{c}\text { Electrical } \\
\text { signals }\end{array}$ & Display \\
\hline Speaker & $\begin{array}{c}\text { Electrical } \\
\text { signals }\end{array}$ & Sound \\
\hline
\end{tabular}
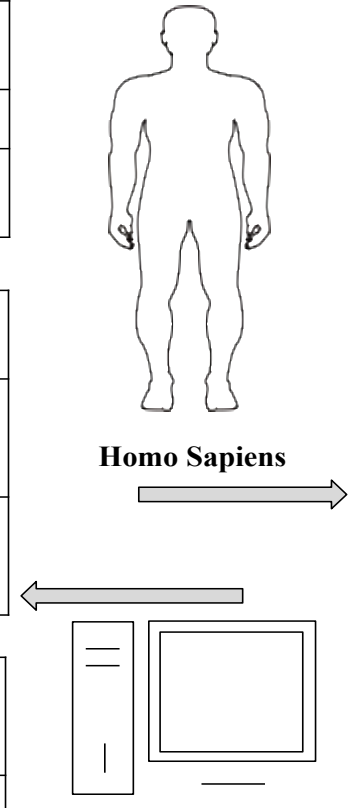

Computer

\begin{tabular}{|c|c|c|}
\hline $\begin{array}{c}\text { Human } \\
\text { Devices }\end{array}$ & $\begin{array}{c}\text { External } \\
\text { Input }\end{array}$ & $\begin{array}{c}\text { Internal } \\
\text { Output }\end{array}$ \\
\hline Eyes & Light & $\begin{array}{c}\text { Electrical nerve } \\
\text { impulses }\end{array}$ \\
\hline Ears & Sound & Electrical impulses \\
\hline Lungs & Air & $\begin{array}{c}\text { Absorb oxygen and } \\
\text { release carbon } \\
\text { dioxide }\end{array}$ \\
\hline
\end{tabular}

\begin{tabular}{|c|c|c|}
\hline $\begin{array}{c}\text { Human } \\
\text { Devices }\end{array}$ & $\begin{array}{c}\text { Internal } \\
\text { Input }\end{array}$ & $\begin{array}{c}\text { Internal } \\
\text { Output }\end{array}$ \\
\hline Heart & Blood & blood Circulation \\
\hline Brain & $\begin{array}{c}\text { Electrical } \\
\text { nerve } \\
\text { impulses }\end{array}$ & $\begin{array}{c}\text { Coordination, } \\
\text { Perception, Store } \\
\text { memories }\end{array}$ \\
\hline
\end{tabular}

\begin{tabular}{|c|c|c|}
\hline $\begin{array}{c}\text { Human } \\
\text { Devices }\end{array}$ & Internal Input & $\begin{array}{c}\text { External } \\
\text { Output }\end{array}$ \\
\hline Larynx & $\begin{array}{c}\text { Electrical } \\
\text { nerve impulses }\end{array}$ & Sound \\
\hline $\begin{array}{c}\text { Voluntary } \\
\text { Muscles }\end{array}$ & $\begin{array}{c}\text { Electrical } \\
\text { nerve impulses }\end{array}$ & Movement \\
\hline
\end{tabular}

Fig. 1. Comparison between Computer and Homo sapiens based on the internal devices

Computers are built with devices so as the Homo sapiens are built with organs (Fig. 1). Some of the devices in both computer and HS, listed in Fig. 1, are completely internal (both input and output). Some are internal but have external output, and some have external input but produce internal output. These comparisons reveal that there is no such device in both 
computer and HS, which takes only external input and provides only external output. However, the computer or HS as a whole might fall into this category (external input and external output). Interestingly, in both case of HS or computer, all of the input has to be processed internally (Fig. 1). This comparison also indicates the missing parts that are necessary to generate an AS - the brain and the memory. Brain processes and coordinates what HS learns through instructions and memory stores those instructions [22].

Building an HS equivalent brain is impossible and unnecessary as well. But a device (for example, a computer), could have a simple 'brain software'. If the existing software of the device is modifiable or programmable by every user to generate new functions, the 'brain software' is necessary to coordinate and process those programming instructions. A memory could also be introduced into the device to store the user's given instructions. Such an instructive device could provide a platform to the development of an AS. But at this point, the most critical aspect of the device is to develop a language by which a device can be instructed or taught to modify or generate its output by its every user.

\section{A Language to TEACH ARTiFicial SAPIENS}

The computer (or any other electronic device) is run by software instructed by the language of the computer [23]. The

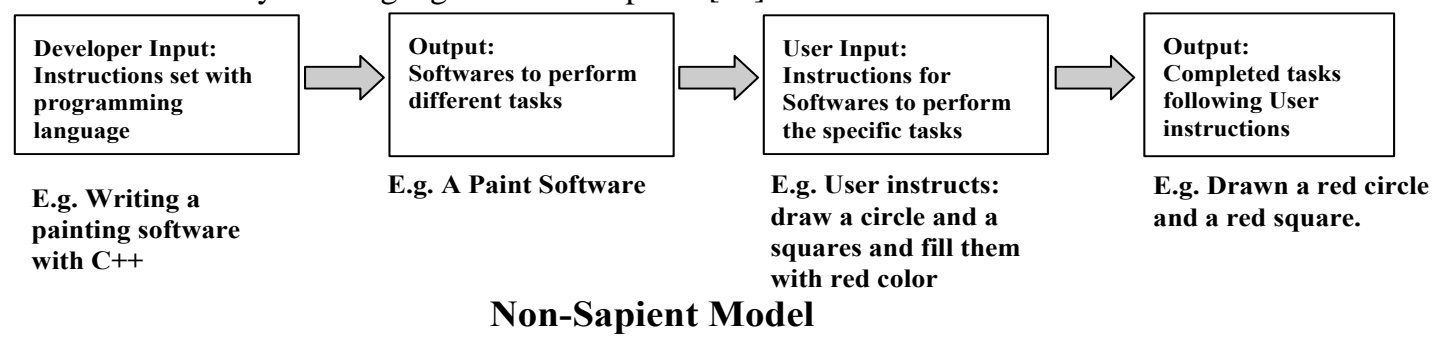

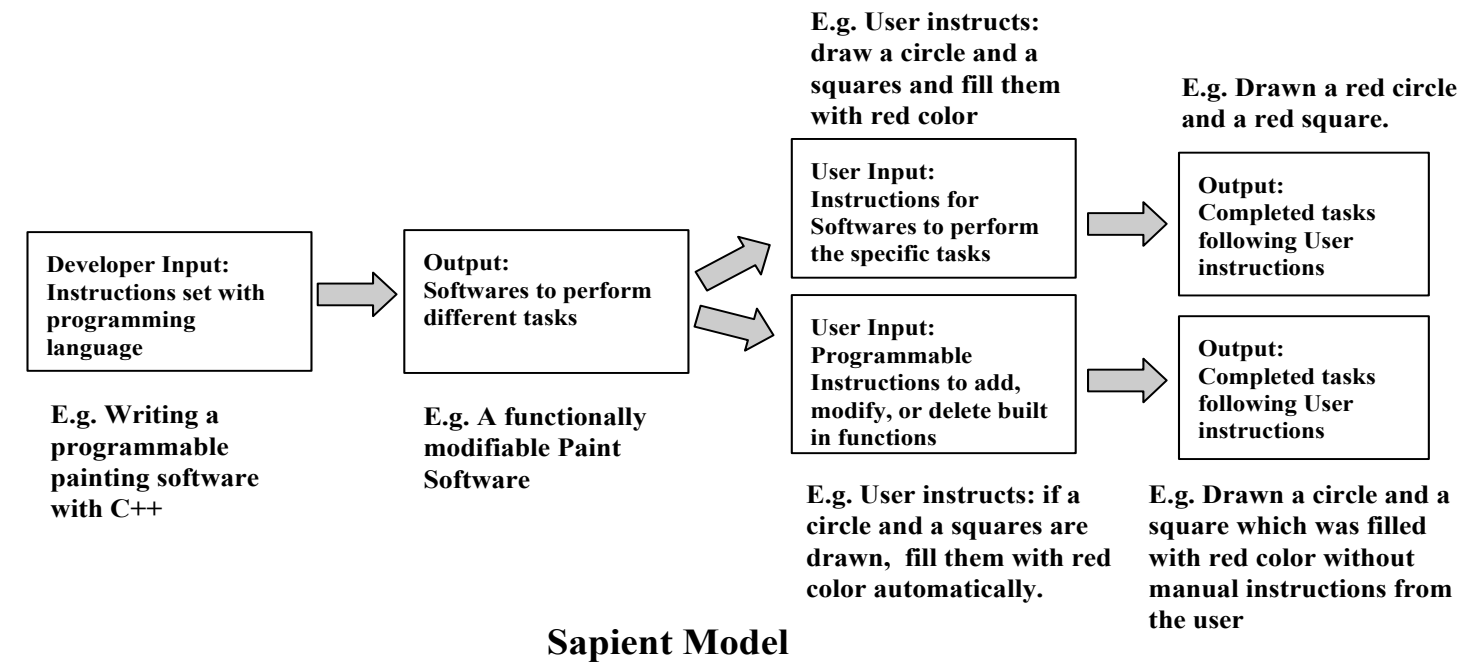

Fig. 2. Scheme to convert a non-sapient model to sapient model

If sapience is attributed to a computer system by its useful knowledge or action, a computer can be made teachable by introducing a second type of extrinsic language - similar to what HS have to learn and communicate. Currently, programmers and developers write software that can take pre- language here is any type of programming language that is used to write any programs for any computational devices [23], [24]. Although programming languages have evolved to fifthgeneration programming languages (5GL), these languages are converting the given instructions into the machine language ultimately to bits ( 0 and 1$)$ [23], [24]. In contrast to the computer's only one distinct type of language (bits), Homo sapiens can have two languages: extrinsic and intrinsic. Extrinsic natural language, which the HS speaks or signs is a means of expressing and communicating ideas, emotions or desires externally with other beings. The other is the intrinsic language inside the human body that all the internal body elements use to communicate with each other for the survival as an entire HS. This intrinsic language of HS, an abstract language idea, is the instructions provided by deoxyribonucleic acids (DNA) and other cellular elements [22]. Intrinsic language accounts for the HS innate biological motivations for gaining knowledge and improving its own intelligence and sapience. Extrinsic language is the external medium for HS to acquire the knowledge, wit and wisdom. The ability of HS to generate salient meanings (intelligent action or knowledge), which is useful to others, comes from what HS learns from its surroundings through the extrinsic language.

\section{Sapient Model}

E.g. User instructs: E.g. Drawn a red circle

Completed tasks following User instructions

Output: Completed tasks following User instructions

g. Drawn a circle and a manual instructions from the user fixed input from the user and generate specific results (Fig. 2). I propose, to make a teachable computer, programmers and developers should make software (e.g. applications in OS) that could be further programmable/modifiable by all of its users (Fig. 2). In this case, a simple universal programming language 
(extrinsic language for the computer) could be developed. This language should be very close to the natural language of the users and accessible to all of the device users through textual or natural language user interfaces.

The theory to render an AS is that when software or applications are programmable such that the users can modify their functional outputs, they could display a level of intelligence or sapience. Example of how this theory could render intelligent and sapient act: current operating systems for mobile devices such as Android or iOS usually contain a Clock application (app) that shows the time and provides time-related utilities (e.g. setting up an alarm). These devices also contain an Stock application that displays real-time stock updates. If the Clock and Stock apps are programmable at a certain level such that its user could teach the stock app to display the closing time stock prices (NY 4:30pm) of what the user bought - this function could be considered as an intelligent act. At the same time, the stock app could also suggest whether the user should sell or keep his or her stock if the app was taught the trend of stocks when its prices go high or low - and this function then could be considered as a sapient act.

A device that is programmable or learnable is the Artificial Sapiens. AS can be made to learn from all of its users and perform the learned functions to every user regardless of whom it learned from (updated through sharing/clouding). If a new user experiences the stock app that just learned to be smart, the user would surely admire such intelligence and sapience level. Following the above example, AS could thus start to exhibit, if not the highest, a low-level wit and wisdom.

Here is another example: nowadays, grouping the emails by priority in a Mail application is very common. Consider an email group named 'VIP'. In an AS system, a user could program or teach it to remind him or her about an unread VIP email every five minutes. The user could also teach that if the email is from his family member and the content has an identifying phrase such as 'very urgent', then the message would constantly pop up with a beep until the user confirms that it has been read. In this case of a newly learned mail app, one could easily deem the first function as an intelligent act and the second function as a sapient act.

While judging an AS, one might ask why not provide all the future possible functions of AS as built-in? This question is similar to the question, why a child is not born as an adult? Big companies like Apple and Google have made their application development platform open to the developers. That's why thousands of unique apps have been and are being created. When all of the apps will become more functional and interconnected by a universal simple programming language, we could expect the evolution of Artificial Sapiens from current non-intellectual operating systems.

\section{CONCLUSION}

I have proposed a plan to achieve human-level artificial intelligence or sapience underlying the fact that humans are the judge to attribute intelligence or sapience based on actions. The proposed way of making devices that are programmable/teachable by each of its users, in principle, is easy to build with the currently available technology. But an
Artificial Sapiens that mimics Homo Sapiens may be many years away.

I proposed to make the current computational devices such that they can learn and be taught by a computational language. The plan would be to convert a computational system to a teachable system, much as a human child gains knowledge and wisdom as the child grows. This teachable system should have built-in facilities for learning (through a language) that is similar to what human infants have. Initially, these teachable systems could be less educable. But at some point, in the future, they could significantly be educated.

My proposal may appeal to researchers with distant interests, as it overlaps the understanding of biological and computer science. Ideally, artificial sapient systems would be an appropriate artifact of biological sapient systems. In the long run, AS are expected to be self-reliable, adaptive, sociallyinteractive and to be competent in the jobs which require collective actions (such as: conforming or co-ordinating a team, arbitration or negotiation).

More understanding on Artificial Sapiens will emerge after they start to learn and interact with the Homo Sapiens. If the proposal I have outlined is followed successfully, one day AS could have the performance of humans and could replace their difficult jobs. The conceptual task of developing Artificial Sapiens may seem formidable, but perhaps the alternative approach that I proposed might prove effectual.

\section{ACKNOWLEDGMENT}

I thank Zinat Sharmin for comments and valuable discussions.

\section{REFERENCES}

[1] C. von Linné, Systema naturae per regna tria naturae secundum classes, ordines, genera, species cum characteribus, differentiis, synonymis, locis; editio duodecima.-. 1766.

[2] P. Baltes, U. Staudinger, and A. Maercker, "People nominated as wise: a comparative study of wisdom-related knowledge.," Psychol., 1995.

[3] S. Ryan, "Wisdom," 2007.

[4] R. V. Mayorga, "A Paradigm for Sapient (Wise) Systems: Implementations, Design\&amp;Operation," in Toward Artificial Sapience, London: Springer London, 2008, pp. 143-173.

[5] T. Karelitz and L. Jarvin, "The meaning of wisdom and its development throughout life," life-span Dev., 2010.

[6] L. I. Perlovsky, "Sapience, Consciousness, and the Knowledge Instinct (Prolegomena to a Physical Theory)," in Toward Artificial Sapience, London: Springer London, 2008, pp. 33-60.

[7] M. van Otterlo, M. Dastani, M. Wiering, and J.-J. Meyer, "A Characterization of Sapient Agents," in Toward Artificial Sapience, London: Springer London, 2008, pp. 129-141.

[8] P. Noriega, "Sapients in a Sandbox," in Toward Artificial Sapience, London: Springer London, 2008, pp. 105-115.

[9] E. Feigenbaum, "Some challenges and grand challenges for computational intelligence," J. ACM, 2003.

[10] NOW, “The Quest for Artificial Intelligence," Cambridge Univ Press.

[11] N. Nilsson, "Human-level artificial intelligence? Be serious!," AI Mag., 2005.

[12] J. McCarthy, "The well-designed child," Artif. Intell., vol. 172, no. 18, pp. 2003-2014, Dec. 2008.

[13] Turing, “Computing machinery and intelligence," Mind, 1950.

[14] Karpathy and L. Fei-Fei, "Deep visual-semantic alignments for generating image descriptions," Proc. IEEE Conf., 2015. 
[15] D. Floreano and C. Mattiussi, Bio-inspired artificial intelligence: theories, methods, and technologies. 2008.

[16] J. William, "Directions for Bio-Inspired Artificial Intelligence," J. Comput. Sci. Syst. Biol., 2012.

[17] P. Bloom, Descartes' baby: How the science of child development explains what makes us human. 2009.

[18] D. Boyd and H. Bee, The developing child. 2012.

[19] Whitworth and H. Ryu, "A comparison of human and computer information processing," 2008.
[20] P. Harris, Children and emotion: The development of psychological understanding. 1989.

[21] T. Minato, Y. Yoshikawa, and T. Noda, "CB2: A child robot with biomimetic body for cognitive developmental robotics," 2007 7th IEEERAS, 2007.

[22] J. Reece, L. Urry, M. Cain, and S. Wasserman, Campbell biology. 2011.

[23] RAJARAMAN AND N. ADABALA, FUNDAMENTALS OF COMPUTERS. 2014.

[24] R. Wexelblat, History of programming languages. 2014. 